\title{
Evidence for Membrane Potential Changes in Isolated Synaptic Membrane Ghosts Monitored with a Merocyanine Dye
}

\author{
Kohtaro KAMINO* and Akira INOUYE** \\ *Department of Physiology, Faculty of Medicine, Tokyo Medical and Dental \\ University, Bunkyo-ku, Tokyo, 113 Japan \\ **Department of Physiology, Faculty of Medicine, \\ Kyoto University, Kyoto, 606 Japan
}

\begin{abstract}
Changes in the fluorescence intensity of merocyanine-540 were measured in suspensions of synaptic plasma membrane ghosts isolated from rat brain cortex. With preincubation of the membrane ghosts in isotonic $\mathrm{KCl}$ or $\mathrm{NaCl}$ solution, $\mathrm{K}$ - and Na-enriched ghosts samples were prepared. In suspensions of both sort of synaptic membrane ghosts, merocyanine- 540 showed a fluorescence emission peak at a wavelength of $590 \mathrm{~nm}$.

Under a fixed total concentration of $\mathrm{NaCl}$ and $\mathrm{KCl}$, high external $\mathrm{K}^{+}$ induced an increase in the fluorescence intensity, such an increase being proportional to logarithm of $\mathrm{K}^{+}$concentration. Replacing $\mathrm{K}^{+}$by $\mathrm{Rb}^{+}$, $\mathrm{NH}_{4}{ }^{+}$or $\mathrm{Cs}^{+}$, a similar effect was observed. $\mathrm{Rb}^{+}$was about as effective as $\mathrm{K}^{+} ; \mathrm{NH}_{4}$ is about $2 / 3$ and $\mathrm{Cs}^{+} 1 / 4$ as effective. But the changes in fluorescence with increasing $\mathrm{K}^{+}$concentration were larger in $\mathrm{K}$-ghosts than in Na-ghosts. $\mathrm{K}^{+}$-induced fluorescence changes were very small when gramicidin $\mathrm{D}$ was added to the suspension. $\mathrm{K}^{+}$-induced fluorescence changes were not observed in ultrasonicated ghost suspensions. Such findings seem to indicate that the $\mathrm{K}^{+}$-ions induced fluorescence increases reflect the depolarization in the isolated synaptic plasma membrane ghosts. Furthermore, the permeability ratio $P_{\mathrm{Na}} / P_{\mathrm{K}}\left(P_{\mathrm{Na}}, P_{\mathrm{K}}\right.$ : the permeability constant for $\mathrm{Na}^{+}$and $\mathrm{K}^{+}$) was estimated to be smaller than 0.03 .
\end{abstract}

The study of the membrane potential of nerve-ending is of primary importance in understanding neuronal function. Being a continuation of axon membraneso called axolemma-the limiting membrane of the nerve-ending serves to regulate the passage of ions, metabolites, and other small molecules, thus maintaining a special milieu for the specific activity of this compartment.

In the previous papers we reported that high external $\mathrm{K}^{+}$-ions caused swelling

Received for publication December 10, 1977

神野耕太郎, 井上 章 
of isolated nerve-ending particles (synaptosomes) (KAMINo et al., 1973), and produced alteration in synaptosomal $\mathrm{Ca}^{2+}$-binding characteristics such as dissociation constant and co-operativity (KAMINo et al., 1974). Such phenomena seem to be closely related to synaptic membrane potential changes. However, unfortunately, the small size of the presynaptic terminals or isolated nerve-ending particles (about $600 \mathrm{~nm}$ diameter) (KAMINO and INOUYE, 1975) precludes direct measurement of presynaptic membrane potentials with conventional microelectrodes.

Fluorescent probes have been used to detect the structural (or conformational) changes that accompany neuron activities ( $c f$. COHEN, 1973; LANDOwnE, 1975). Recently, certain fluorescent dyes have been found to accurately indicate membrane potential changes in axons of squid (CoHEN et al., 1974; Ross et al., 1977; Cohen et al., unpublished results), and it has been demonstrated that these dyes are useful as the molecular probes of membrane potential in systems where electrodes cannot be used (CoHEN et al., 1974). Of the dyes that exhibit a fluorescence response in squid giant axon, merocyanine-540 is one of the more sensitive dyes, and of impermeant dyes; its signal is detectable with a signal-to-noise ratio greater than 10: 1 (DAvila et al., 1973). The efficacy of this dye has been demonstrated in the detecting the membrane potentials in leech segmental ganglia (DAVILA et al., 1973; SAlZBerg et al., 1973), cardiac muscle (SAlAma and Morad, 1976), and skeletal muscle (LANDOWNE, 1974). Other dyes also have been used in the measurement of membrane potentials in suspensions of human red cells (HoFFMAN and LARIS, 1974), mitochondria (TEDESCHI, 1974), and Ehrlich ascites tumor cells (LARIS et al., 1976). Using 3,3'-dialkyl-2,2'-oxacarbocyanine dye (diO-C - $_{5}-(3)$ ), BLAUSTEIN and GOLDRING (1975) had already demonstrated the potassium diffusion potentials in intact synaptosomes. This dye is one of permeant dyes.

In the present study, merocyanine-540 was used to investigate the extrinsic fluorescence changes in isolated synaptic membrane ghosts as a consequence of altering the external/internal $\mathrm{K}^{+}$-ion concentration gradient. The results are discussed in relation to membrane potentials.

\section{MATERIALS AND METHODS}

Preparation of synaptic membrane ghosts. Essentially the same methods as those used in previous work (KAMINo et al., 1973) were employed in the preparation of synaptosomes. Pooled cortical tissues of rat brain (usually 2-3 brains) were homogenized in $0.32 \mathrm{M}$ sucrose by a Teflon-glass homogenizer of Potter-Elvejem type, after which the crude mitochondrial fractions were subjected to sucrose density gradient centrifugation $(64,000 \times g$ for $60 \mathrm{~min})$ using Hitachi preparative ultracentrifuge (Type HU65p). The material, i.e., synaptosomes, at the 0.8 to $1.2 \mathrm{M}$ interface was subjected to the subfractionation of synaptic membrane.

The synaptic membrane ghosts were prepared according to a procedure based on that originally described by GRAY and WhITTAKeR (1962). After the synapto- 
somes were disrupted by osmotic lysis in distilled water at $0^{\circ} \mathrm{C}$, the water suspension of synaptosomes was subjected to the density gradient centrifugation at $64,000 \times g$ for $60 \mathrm{~min}$.

The material at the $0.8-1.0 \mathrm{M}$ interface of discontinuous density sucrose gradients was carefully removed using a pipet with a fine tip and diluted in 5 volume with $15 \mathrm{~mm}$ Tris-HCl buffer solution $(\mathrm{pH} \mathrm{7.3)}$ and spun down at $12,000 \times g$ for $60 \mathrm{~min}$. The resultant pellets were suspended in buffered $170 \mathrm{~mm} \mathrm{KCl}(\mathrm{K}$ ghosts) or $\mathrm{NaCl}$ (Na-ghosts) solution and spun down at $20,000 \times g$ for $60 \mathrm{~min}$. The final pellets of $\mathrm{K}$ - or Na-ghosts thus obtained were suspended in buffered salt solutions after washing twice with each buffered salt solution. After preincubation in isotonic $\mathrm{KCl}$ or $\mathrm{NaCl}$ medium overnight at $0^{\circ} \mathrm{C}$, the final pellet of $\mathrm{K}$ - or $\mathrm{Na}$ ghosts separated by centrifugation were suspended in appropriate buffered salt solutions after washing twice with each buffered salt solutions.

Protein was determined by the method of Lowry et al. (1951), using bovine serum albumine as a standard.

Electron-microscopic observation. After $1 \mathrm{hr}$ in $3 \%$ glutaraldehyde buffered with Millonig's phosphate buffer at 7.3, a portion of the synaptic membrane ghost pellets was washed in buffer, postfixed in $1 \% \mathrm{OsO}_{4}$ in Dalton's buffer ( $\mathrm{pH} 7.3$ ) for overnight at $0^{\circ} \mathrm{C}$, dehydrated in ethanol, embedded in Epon, and observed in a Hitachi electron microscope (HU-11) after thin-sectioning.

Light-scattering measurement. The light-scattering measurement used in the present study and method of estimation of volume changes of the ghosts were the same as those employed in our previous papers (KAMINo et al., 1973; KAMINO and INOUYE, 1975).

$\mathrm{K}^{+}$and $\mathrm{Na}^{+}$contents of synaptic membrane ghosts. After the pellets of synaptic membrane ghosts preincubated in isotonic $\mathrm{K}^{+}$or $\mathrm{Na}^{+}$solution overnight were ruptured by means of ultrasonication (KONTS micro-ultrasonic cell disrupter, $\mathrm{K}-881440)$ at $687 \mathrm{~W}$ per square inches of power in the frequency of $23.500 \mathrm{C} / \mathrm{S}$ for $30 \mathrm{~min}$ at $0^{\circ} \mathrm{C}$, the suspension was centrifuged at $40,000 \times g$ for $60 \mathrm{~min}$. The $\mathrm{K}^{+}$ and $\mathrm{Na}^{+}$ion concentrations in these suspensions were then determined with a flame photometer (Hitachi flame photometer, Type 205).

Fluorescence measurements. Fluorescence was measured with a Shimadzu fluorescence spectroscopic photometer (RF 501) with a $500 \mathrm{~W}$ xenon arc lamp. All measurements were carried out at room temperature $\left(20-23^{\circ} \mathrm{C}\right)$. The fluorescence intensity was recorded with a Shimadzu U-125 MO recorder. Initial volume in the cuvette was $3 \mathrm{ml}$. The ghosts suspensions were stirred magnetically with a circular stirrer inside a standard $1 \mathrm{~cm}$ path length quartz cuvette. The intensity of fluorescence from the synaptic membrane ghosts suspension was measured with the ghost concentration in the range from 50 to $200 \mu \mathrm{g}$ protein per $\mathrm{ml}$.

To minimize contamination with dust particles, all the solutions used for the fluorescence measurements were passed through a Millipore filter (Gelman Instrument Co., pore size $100 \pm 8 \mathrm{~nm}$ ) under pressure. 
5-3-sodium sulfopropyl-2(3H)-benzoxazolyliden-2-butenylidene-1,3-dibutyl-2thiobarbituric acid (merocyanine-540) was purchased from Eastman Kodak Co. This dye is impermeant to biological membrane (WAGGONER, 1976). It has recently been shown that the fluorescence of an axon stained with this dye increases during the action potential (COHEN et al., 1974). They demonstrated in their voltage clamp experiment on a squid axon (Loligo pealii) that the fluorescence of this dye is linearly related to membrane potential over the range of $\pm 100 \mathrm{mV}$ from the resting potential; depolarization caused an increase in fluorescence.

\section{RESULTS}

Electron micrograph and some configurational characteristics of isolated synaptic membrane ghosts

A representative picture of a thin section of the isolated synaptic plasma membrane ghosts is presented in Fig. 1. This micrograph definitely establishes

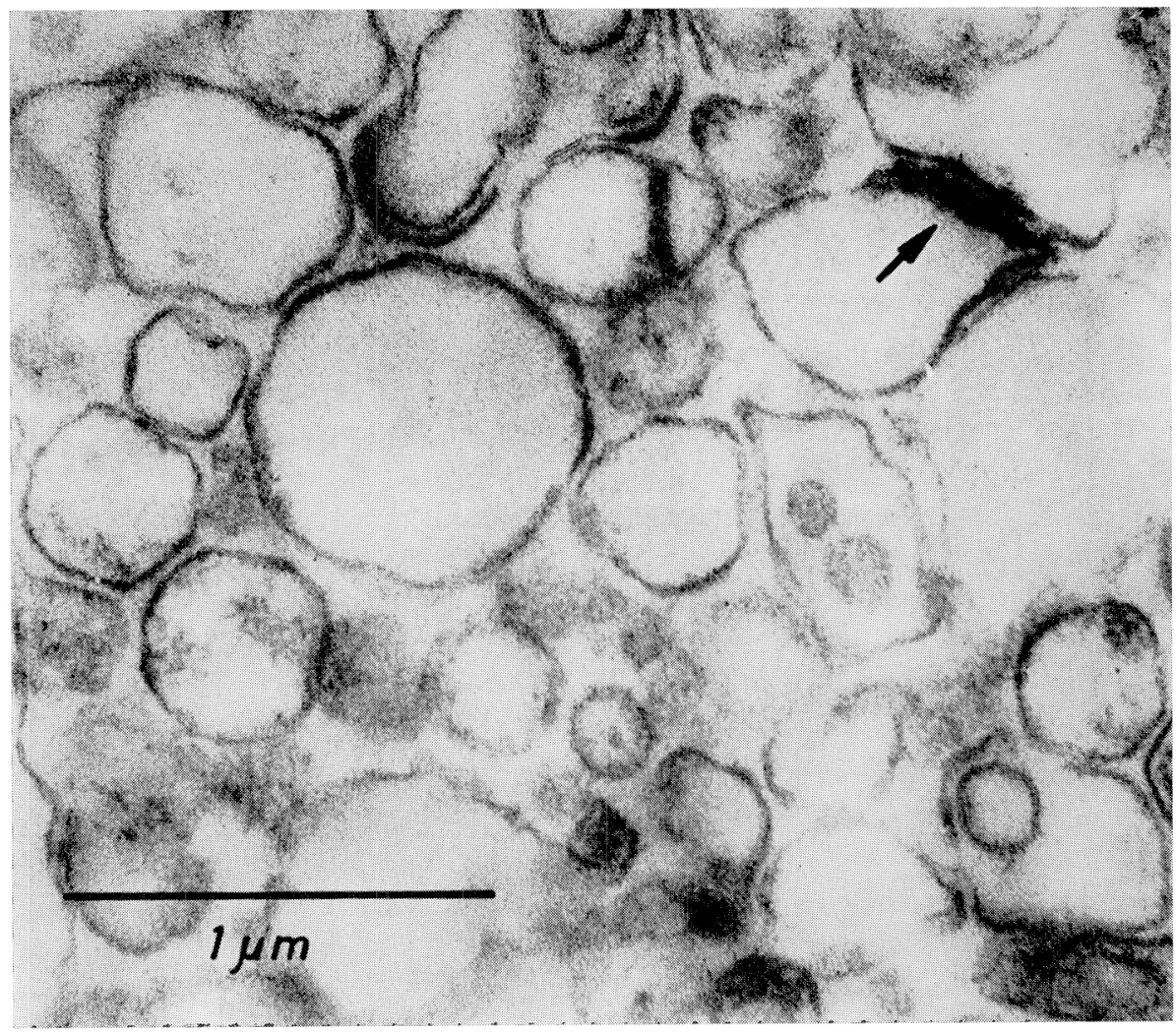

Fig. 1. Electron micrograph of isolated synaptic membrane ghosts in thin section (glutaraldehyde-osmium-Epon). Synaptic membrane ghosts are sealed structures. Arrow indicates postsynaptic membrane. 
that the preparations are essentially composed of nearly spherical microsacks ranging in diameter from 300 to $800 \mathrm{~nm}$, which are closed and limited by an apparently intact synaptic plasma membrane. The size is the same as that of intact synaptosomes. Some ghosts are associated with postsynaptic membrane. We can find about one mitochondrion per 100 ghosts and one synaptic vesicle per 1,000 ghosts. This contamination is not significant.

Utilizing a light-scattering technique, as shown in Fig. 2, it was confirmed that the isolated synaptic membrane ghosts in sucrose solutions of various osmotic concentrations behaved as osmometers obeying the simple Boyle-van't Hoff's relation;

$$
\Pi\left(v-v_{\mathrm{d}}\right)=\text { constant, }
$$

where $v$ is relative volume of the ghosts, $v_{\mathrm{d}}$ the osmotic dead space and $\Pi$ osmotic concentration of the medium. This implies that basic structure of the isolated synaptic membrane is inact, and the isolated synaptic membrane ghosts have sealed structures.

Fluorescence of merocyanine-540 in synaptic membrane ghosts

Potassium ion-induced change in fluorescence. In this experiment, two varieties of synaptic membrane ghosts were used: one was "K-ghosts" which were preincubated in isotonic $(170 \mathrm{~mm}) \mathrm{KCl}$ solution containing $15 \mathrm{~mm}$ Tris- $\mathrm{HCl}$ buffer $\left(\mathrm{pH}\right.$ 7.3) overnight at $0^{\circ} \mathrm{C}$, and the other "Na-ghosts" which preincubated in

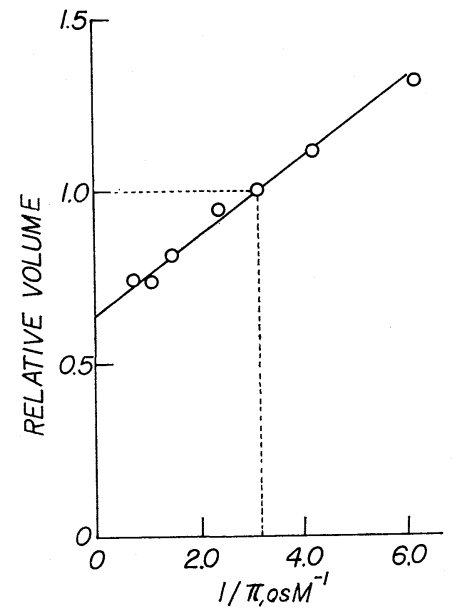

Fig. 2
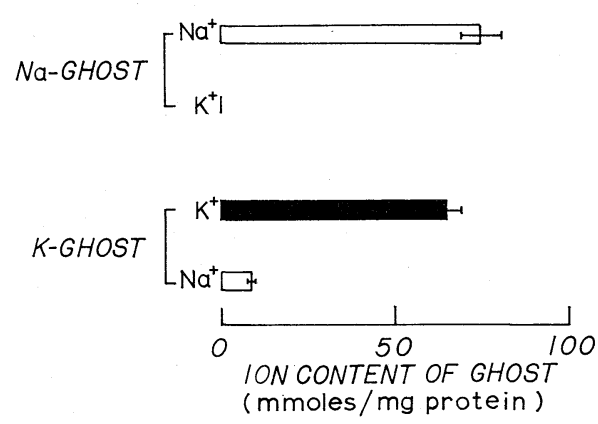

Fig. 3

Fig. 2. Relationship between the reciprocal of osmotic concentration of sucrose and relative volume $(v)$ of ghosts. $\quad v$ is the normalized volume to that in 0.32 osM sucrose.

Fig. 3. Internal $\mathrm{K}^{+}$and $\mathrm{Na}^{+}$concentration of the two varieties of synaptic membrane ghosts. Concentrations are represented in mu per $\mathrm{mg}$ protein of synaptic membrane. The internal cation of the K-ghosts is all $\mathrm{K}^{+}$and that of the Na-ghosts all $\mathrm{Na}^{+}$. 
isotonic $\mathrm{NaCl}$ solution for the same period of time. The internal cation species in these ghosts were expected to be $\mathrm{K}^{+}$in the former and to be $\mathrm{Na}^{+}$in the latter. It is, however, very difficult to determine exactly the internal cation concentrations in these samples, because we cannot estimate exactly the volume of ghosts. Therefore, we estimated the relative value of the cation contents of the ghost pellet. The cation contents of the $\mathrm{K}$-ghosts and Na-ghosts in mmoles per $\mathrm{mg}$ protein is shown in Fig. 3. It is clear that the internal cation of the K-ghosts was almost exclusively $\mathrm{K}^{+}$and that of the Na-ghosts was $\mathrm{Na}^{+}$.

Typical fluorescence emission spectra with $570 \mathrm{~nm}$ excitation wavelength of the isolated synaptic membrane ghost (K-ghosts) suspension in isotonic $\mathrm{NaCl}$ or $\mathrm{KCl}$ medium containing merocyanine-540 $\left(1.2 \times 10^{-5} \mathrm{~g} / \mathrm{ml}\right)$ are illustrated in Fig. 4. As shown in Fig. 4, in isotonic (170 mM) NaCl- or KCl-solution (pH 7.3, $15 \mathrm{~mm}$ Tris- $\mathrm{HCl}$ buffer) without synaptic membrane ghosts, the fluorescence emission intensity of the dye was very small. This curve is due to light-scattering. The addition of the ghosts to a salt solution containing merocyanine- 540 results

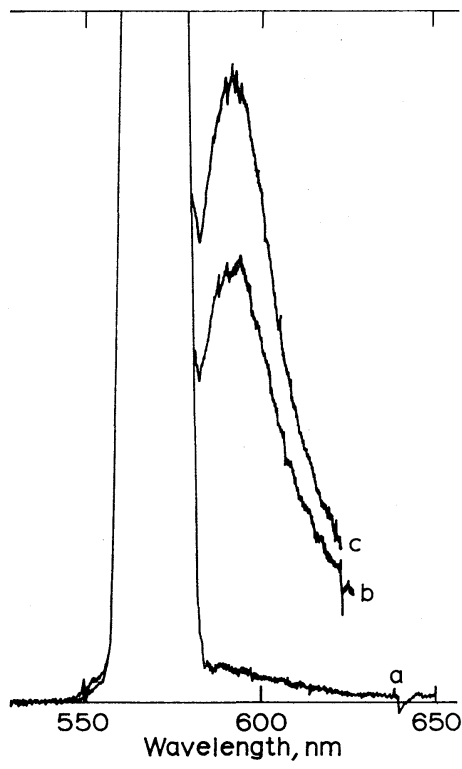

Fig. 4

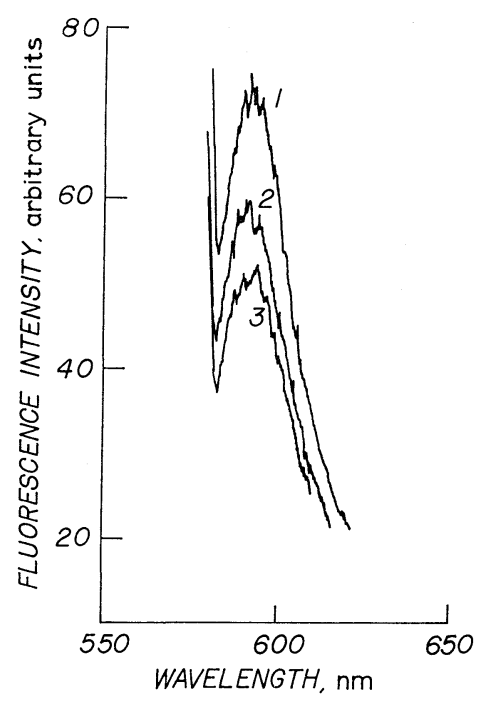

Fig. 5

Fig. 4. Emission spectrum of merocyanine-540 $\left(1.2 \times 10^{-5} \mathrm{~g} / \mathrm{ml}\right)$ in suspension $(402 \mu \mathrm{g}$ protein/ml) of the K-ghosts in $170 \mathrm{mM} \mathrm{KCl}$ (curve c) or $\mathrm{NaCl}$ (curve b) solution containing $15 \mathrm{~mm}$ Tris- $\mathrm{HCl}$ buffer ( $\mathrm{pH}$ 7.3). Fluorescent intensity was measured with excitation at $570 \mathrm{~nm}$. Curve a is the spectrum in $170 \mathrm{~mm} \mathrm{NaCl}$ or $\mathrm{KCl}$ solution $(15 \mathrm{~mm}$ Tris- $\mathrm{HCl}$ buffer, $\mathrm{pH} 7.3$ ) without the membrane ghosts. The peaks at around $570 \mathrm{~nm}$ are due to light scattering. Temp., $22^{\circ} \mathrm{C}$.

Fig. 5. Emission spectrum of merocyanine-540 bound to the K-ghosts suspended in $170 \mathrm{~mm}$ $\mathrm{KCl}$ (curve 1), $70 \mathrm{~mm} \mathrm{KCl}$ and $100 \mathrm{~mm} \mathrm{NaCl}$ (curve 2), or $170 \mathrm{~mm} \mathrm{NaCl}$ (curve 3) solutions containing $15 \mathrm{~mm}$ Tris- $\mathrm{HCl}$ buffer ( $\mathrm{pH} 7.3$ ). Excitation wavelength was $570 \mathrm{~nm}$. 
in a rapid increase in fluorescence intensity. The emission spectrum under these conditions was found to have a peak emission at around $590 \mathrm{~nm}$ with $570 \mathrm{~nm}$ excitation wavelength. The increments were identical whether ghosts are added to the dye solution or the dye to a ghost suspension. Fluorescence change was fast and reached to the steady level within 30-60 sec. The magnitude of the fluorescence intensity at a wavelength of $590 \mathrm{~nm}$ appeared proportional to the amount of the ghosts added up to $400 \mu \mathrm{g}$ protein per $\mathrm{ml}$. The fluorescence increase induced by addition of the membrane ghosts was not accompanied by a shift in the wavelength of peak emission as would be found with the dye ANS (Kamino, unpublished result).

From spectra traced in Figs. 4 and 5, it is obvious that the fluorescence emission spectra of merocyanine-540 is partly modified by scattering. Strictly speaking, a peak observed at a wavelength of $590 \mathrm{~nm}$ is composed of fluorescence and scattering. Subtracting the scattering intensity, therefore, we corrected the observed intensity to obtain fluorescence in Figs. 6, 7 and 8.

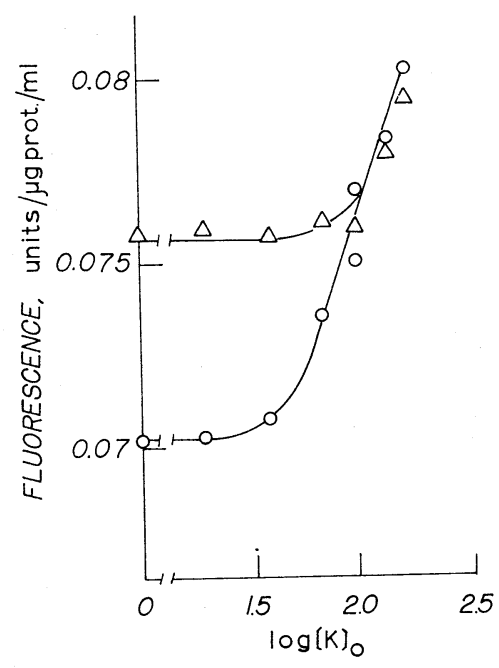

Fig. 6

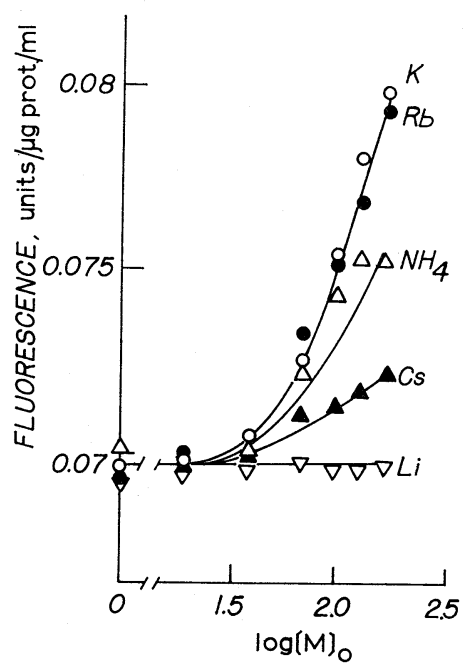

Fig. 7

Fig. 6. Relationship between fluorescence of merocyanine-540 bound to the K-ghosts or Naghosts and $\mathrm{K}^{+}$concentration in medium. Dye concentrations were $1.2 \times 10^{-5} \mathrm{~g} / \mathrm{ml}$. Fluorescence intensities at a wavelength of $590 \mathrm{~nm}$ were measured with excitation at $570 \mathrm{~nm}$. Fluorescence intensities were corrected by subtracting light scattering intensity from the intensity at a wavelength of $590 \mathrm{~nm}$. $\triangle$, in Na-ghost suspension; O, K-ghost suspension. Temp., $22^{\circ} \mathrm{C}$. $[\mathrm{K}]_{\mathrm{o}}$ is in $\mathrm{mm}$.

Fig. 7. Relationship between alkali metal ion concentration $[\mathrm{M}]_{0}$, and fluorescence of merocyanine-540 in K-ghost suspension. Dye concentrations were $1.2 \times 10^{-5} \mathrm{~g} / \mathrm{ml}$. Fluorescence intensities at a wavelength of $590 \mathrm{~nm}$ were measured with excitation at $570 \mathrm{~nm}$. Temp., $22^{\circ} \mathrm{C} . \quad[\mathrm{M}]_{0}$ is in mM. $O$, in $\mathrm{KCl}$; $\bullet$, in $\mathrm{RbCl} ; \triangle$, in $\mathrm{NH}_{4} ; \mathbf{\Lambda}, \mathrm{CsCl}$; $\nabla, \mathrm{LiCl}$. 


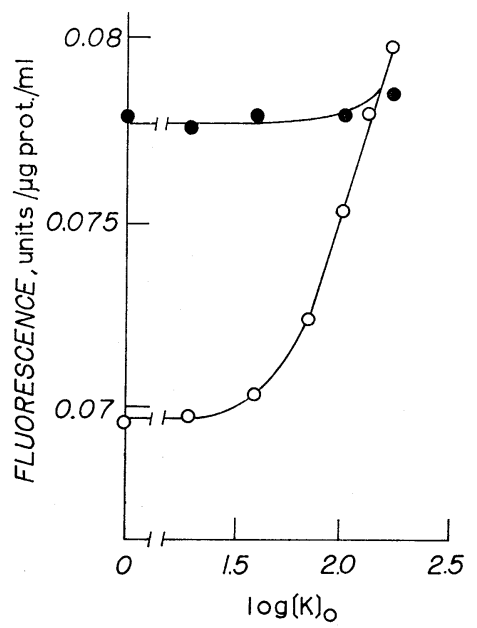

Fig. 8. Effect of gramicidin D on the relationship between fluorescence of merocyanine-540 in $\mathrm{K}$-ghost suspension and $\log [\mathrm{K}]_{0} . \quad 10 \mu \mathrm{g} / \mathrm{ml}$ gramicidin $\mathrm{D}$ was present in suspensions. $[\mathrm{K}]_{\mathrm{o}}$ is in $\mathrm{mm}$. $\quad$, in the presence of gramicidin $\mathrm{D} ; \mathrm{O}$, in the absence of gramicidin $\mathrm{D}$.

When the $\mathrm{K}$-ghosts were suspended in isotonic $(170 \mathrm{~mm}) \mathrm{KCl}$ solution containing merocyanine- 540 at $2.5 \times 10^{-5} \mathrm{~g} / \mathrm{ml}$, the fluorescence intensity was greater than that in isotonic $\mathrm{NaCl}$ solution (Fig. 5). Figure 5 shows a series of fluorescence spectra of merocyanine-540 associated with isolated synaptic membrane ghosts in which the concentration of $\mathrm{Na}\left([\mathrm{Na}]_{0}\right)$ and $\mathrm{K}\left([\mathrm{K}]_{\mathrm{o}}\right)$ in the medium were varied but the sum of $[\mathrm{Na}]_{\mathrm{o}}+[\mathrm{K}]_{\mathrm{o}}$ retained $170 \mathrm{~mm}$. When the fluorescence intensity is plotted against $\log [\mathrm{K}]_{0}$, as shown in Fig. 6, an approximately linear relationship is obtained within the range of more than $40 \mathrm{~mm}$ of external $\mathrm{K}^{+}$concentration. This relationship is very similar to that found with 3,3'-dipropyl-2,2'-oxacarbocyanine diO- $\mathrm{C}_{5}-(3)$ in intact synaptosomes (BLAUSTEIN and GoldRING, 1975). The curve is reminiscent of Nernst's relationship between membrane potential and external $\mathrm{K}^{+}$concentration. It must be noted here that the increase in merocyanine540 fluorescence is associated with depolarization in squid axons. Indeed, BLAUSTEIN and GoldRING (1975) concluded that $\mathrm{K}^{+}$-ion induced increase in fluorescence was attributable to depolarization of synaptosomal membrane produced by external $\mathrm{K}^{+}$.

In the experiments using the Na-ghosts, high external $\mathrm{K}^{+}$-ions also caused an increase in the fluorescence. As shown in Fig. 6, however, its curve of fluorescence $v s . \log [\mathrm{K}]$ o was quite different from that with the K-ghosts: in low $\mathrm{K}^{+}$concentration the fluorescence (represented in fluorescence units per $\mathrm{mg}$ protein per $\mathrm{ml}$ ) in the Na-ghosts was about 1.5 times as large as that in the K-ghosts. Within the range of $[\mathrm{K}]_{0} \geq 70 \mathrm{mM}$, the fluorescence in the Na-ghosts increased linearly with $\log [\mathrm{K}]_{0}$, and its slope was almost parallel to that in the $\mathrm{K}$-ghosts. 


\section{Effects of other alkali metal ions}

Alkali metal ions produce depolarization in excitable cells (SHANES, 1958; AdRIAN and Slayman, 1966). The ions such as $\mathrm{Cs}^{+}$or $\mathrm{Rb}^{+}$also increase merocyanine-540 fluorescence in the synaptic membrane ghosts suspension. As shown in Fig. $8, \mathrm{Rb}^{+}$caused the increase in fluorescence to about the same extent as did $\mathrm{K}^{+}$. About five times as much $\mathrm{Cs}^{+}$as $\mathrm{K}^{+}$was required to produce a given level of the fluorescence increase. $\mathrm{NH}_{4}{ }^{+}$-ions also brought about the fluorescence increase. Complete replacement of $\mathrm{Na}^{+}$by $\mathrm{Li}^{+}$had practically no influence on the fluorescence in synaptic membrane ghosts. To summarize, the order of alkali cations in their ability to increase the fluorescence is as follows:

$$
\mathrm{K}^{+} \simeq \mathrm{Rb}^{+}>\mathrm{NH}_{4}^{+}>\mathrm{Cs}>\mathrm{Na}^{+} \fallingdotseq \mathrm{Li}^{+} \text {. }
$$

These results are consistent with those found with diO- $\mathrm{C}_{5}-(3)$ in intact synaptosomes (Blaustein and Goldring, 1975). We also could confirm the same results in the intact synaptosomes using merocyanine-540. This order of ions corresponds to that of ability to depolarize excitable cells (Adelman and SenFT, 1968).

\section{Effects of gramicidin D}

The application of agents known to depolarize cells by altering the permeability of membranes to ions should provide a test for the hypothesis that the fluorescence changes in this experiment are due to the $\mathrm{K}^{+}$-diffusion potential (BLAUSTEIN and GolDRING, 1975). Gramicidin D is an ionophore which is known to make biological membranes (Podleski and Changeaux, 1969), including of synaptosomes (KeEn and White, 1971; Blaustein and Goldring, 1975), indiscriminately permeable to $\mathrm{Na}^{+}$and $\mathrm{K}^{+}$. The addition of $10 \mu \mathrm{l}$ of a $3 \mathrm{mg} / \mathrm{ml}$ ethanol solution of gramicidin $\mathrm{D}$ markedly increased the fluorescence of the $\mathrm{K}$-ghosts suspended in a solution containing $\mathrm{NaCl}(130 \mathrm{~mm})$ and $\mathrm{KCl}(40 \mathrm{~mm})$. Ethanol alone had no significant effect. The effect of Gramicidin D on the Na-ghosts was smaller than that on the K-ghosts.

These are the results to be expected if the action of gramicidin $\mathrm{D}$ is due primarily to an increase of $\mathrm{Na}^{+}$permeability (PoDLESKI and CHANGEAUX, 1969). So, in low concentration of external $\mathrm{Na}^{+}$, increasing $\mathrm{Na}^{+}$permeability should cause little change in membrane potential. As shown in Fig. 8, gramicidin D increased fluorescence of synaptic membrane ghosts suspended in isotonic $\mathrm{NaCl}$ solution to about the value observed in $150 \mathrm{mM}-\mathrm{K}$ saline: however, gramicidin D had little effect of the fluorescence of synaptic membrane ghosts in isotonic $\mathrm{KCl}$ solution. From these results, it was suggested that $\mathrm{K}^{+}$-ion induced fluorescence changes (Figs. 4 and 5) are closely related to the depolarization. The results in synaptic membrane ghosts are consistent with those in intact synaptosomes (Blaustein and Goldring, 1975). Furthermore, Podleski and Changeaux (1969) demonstrated that Gramicidin A depolarized electroplax to about $0 \mathrm{mV}$. If their observations are applicable to the present study, Fig. 8 may indicate that fluorescence in $150 \mathrm{mM}-\mathrm{K}$ and $20 \mathrm{~mm}-\mathrm{Na}$ mixture solution is approximately equi- 
valent to membrane potential of $0 \mathrm{mV}$.

\section{Effects of ultrasonication}

In the present study, if the fluorescence changes produced by high external $\mathrm{K}^{+}$ions are due to depolarization in synaptic membrane ghosts, such changes should not be observed in the membrane fragments. Using an ultrasonicater (KONTS, $\mathrm{K}-881440$ ), ghosts received ultrasonic irradiation at power of $687 \mathrm{~W}$ per square inches in the frequency of $23,500 \mathrm{C} / \mathrm{S}$ for $30 \mathrm{~min}$ at $0^{\circ} \mathrm{C}$. In such sonicated samples, we could not observe a difference in fluorescence between $\mathrm{KCl}$ and $\mathrm{NaCl}$ solutions (Fig. 9). This result indicates that only in the sealed ghosts did the $\mathrm{K}^{+}$-ion induced fluorescence change appear.

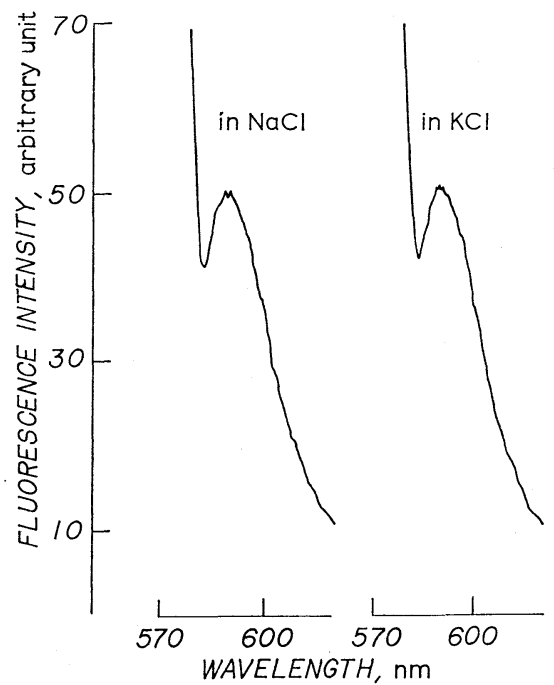

Fig. 9. Emission spectrum of merocyanine-540 in ultrasonicated ghost suspensions in $170 \mathrm{~mm} \mathrm{KCl}$ or $170 \mathrm{~mm} \mathrm{NaCl}$ solution containing $15 \mathrm{~mm}$ Tris- $\mathrm{HCl}$ buffer ( $\mathrm{pH} 7.3$ ). $\mathrm{K}^{+}$-induced change in fluorescence is not observed. Fluorescence was measured with excitation at $570 \mathrm{~nm}$. Dye concentration was $1.2 \times 10^{-5} \mathrm{~g} / \mathrm{ml}$. K-ghosts $(353 \mu \mathrm{g}$ $\operatorname{prot} / \mathrm{ml}$ ) was used.

\section{DISCUSSION}

The experimental results on electron micrograph and osmotic behavior indicate clearly that the separation of synaptic membranes during cell fractionation leads to resealing of the plasma membrane and reformation of a closed structure. The fluorescence of a number of dyes is directly proportional to the membrane potential in the squid giant axon (COHEN et al., 1974; Ross, et al., 1977), suggesting that optical monitoring of the membrane potential changes could be used in biological suspensions including isolated synaptic membrane ghosts. Indeed, 
it was demonstrated that estimates of the membrane potentials of Amphiuma red cells based on studies of fluorescence were in good argeement with those obtained with microelectrode techniques (HoFFMAN and LARIS, 1974).

The changes in fluorescence of merocyanine-540 were demonstrated to be a linearly related to the membrane potential in squid giant axon (COHEN et al., 1974). Although it is impossible to measure directly the membrane potential in the isolated synaptic membrane ghosts, the following evidences indicate that the $\mathrm{K}^{+}$-ion induced increases in fluorescence reflect the depolarization of the membrane:

1. The fluorescence increased approximately in proportion to $\log [\mathrm{K}]_{0}$.

2. Magnitude of the fluorescence intensities correspond to the depolarizing power of alkali metal ions.

3. The fluorescence in the Na-ghosts was, in its magnitude, different from that in the K-ghosts: this result suggests that the former is depolarized more than the latter.

4. The $\mathrm{K}^{+}$-ions induced fluorescence changes disappeared in the presence of gramicidin $\mathrm{D}$ which is an ionophore for $\mathrm{Na}^{+}$.

5. In the ultrasonically disrupted samples, the $\mathrm{K}^{+}$-ion induced changes in the fluorescence could not be observed.

According to the constant field equation (Goldman, 1943; HodGKIN and KATZ, 1949), the membrane potential, $V$, of the isolated synaptic membrane ghosts in these experiments is expressed as

$$
V=\frac{R T}{F} \ln \frac{P_{\mathrm{K}}[\mathrm{K}]_{\mathrm{o}}+P_{\mathrm{Na}}[\mathrm{Na}]_{\mathrm{o}}}{P_{\mathrm{K}}[\mathrm{K}]_{\mathrm{i}}+P_{\mathrm{Na}}[\mathrm{Na}]_{\mathrm{i}}}
$$

ignoring permeability to ions other than $\mathrm{K}$ and $\mathrm{Na}$, or with $p=P_{\mathrm{Na}} / P_{\mathrm{K}}$ :

$$
V=\frac{R T}{F} \ln \frac{[\mathrm{K}]_{\mathrm{o}}+p[\mathrm{Na}]_{\mathrm{o}}}{[\mathrm{K}]_{\mathrm{i}}+p[\mathrm{Na}]_{\mathrm{i}}}
$$

where $R, T$ and $F$ have their usual thermodynamic meaning; $P_{\mathrm{Na}}, P_{\mathrm{K}}$, the permeability constants for $\mathrm{Na}^{+}$and $\mathrm{K}^{+} ;[\mathrm{Na}]_{0},[\mathrm{~K}]_{0}, \mathrm{Na}^{+}, \mathrm{K}^{+}$concentrations (more strictly speaking activities) of the medium and $[\mathrm{Na}]_{\mathrm{i}},[\mathrm{Na}]_{\mathrm{o}}$, those of the inside of the ghosts. Since chloride ions are assumed to be in equilibrium, the terms of chloride ions are omitted. Assuming that the fluorescence in the isolated synaptic membrane ghosts is proportional to $V$, the analogous expression for fluorescence, $F$, is:

$$
F=\alpha \log \frac{[\mathrm{K}]_{\mathrm{o}}+p[\mathrm{Na}]_{\mathrm{o}}}{[\mathrm{K}]_{\mathrm{i}}+p[\mathrm{Na}]_{\mathrm{i}}}+\beta
$$

where $\alpha$ and $\beta$ are constants. The value of $p$ for the neuronal membrane is usually small at resting state; for instance, $p \simeq 0.04$ for squid axon (HodGKIN and KATZ, 1949). Since $[\mathrm{K}]_{\mathrm{i}}$ and $[\mathrm{Na}]_{\mathrm{i}}$ might be regarded as constant, therefore this Eq. (3) may be written as

$$
F=\alpha \log \left\{p k+(1-p)[\mathrm{K}]_{0}\right\}+\beta^{\prime},
$$


where $k=[\mathrm{K}]_{0}+[\mathrm{Na}]_{0}$ and $\beta^{\prime}$ a newly introduced constant including the term of $[\mathrm{Na}]_{\mathrm{i}}$ and $[\mathrm{K}]_{\mathrm{i}}$. Fitting the Eq. $\left(3^{\prime}\right)$ for the curve of $F$ vs. $\log [\mathrm{K}]_{\mathrm{o}}$ results in $p \leq 0.03$ : if $p>0.03$ the Eq. (3) for $F$ as a function of $[\mathrm{K}]_{\mathrm{o}}$ cannot represent the experimental results. This value is of the same order as the result $\left(P_{\mathrm{K}} \simeq 20 P_{\mathrm{Na}}\right)$ obtained by BLAUSTEIN and Goldring $(1975)$ and that $\left(P_{\mathrm{K}} \simeq 19 P_{\mathrm{Na}}\right)$ by KEEN and White (1971) in intact synaptosomes. The results in Fig. 8 suggest that $P_{\mathrm{K}} \simeq$ $P_{\mathrm{Rb}} \simeq 1.5 P_{\mathrm{NH}_{3}} \simeq 4 P_{\mathrm{Cs}}$ for the isolated synaptic membrane, values which are close to those of other excitable membranes ( $c f$. Shanes, 1958; Adrian and Slayman, 1966). The effects of gramicidin D may also be evaluated in terms of Eq. (3); the effect of altered $[\mathrm{Na}]_{o}$ and $[\mathrm{Na}]_{i}$, i.e. a large increase in $p$ should cause a depolarization and a concomitant increase in the fluorescence.

It is interesting to compare the fluorescence change with that in other tissues. In $\mathrm{K}$-ghosts, the fluorescence change, $\Delta F / F \doteqdot 0.27 / \mathrm{mV}$ was estimated. This value is very similar to $0.14 / \mathrm{mV}$ obtained in skeletal muscle (OETLIKER et al., 1975) and $0.2 / \mathrm{mV}$ in cardiac muscle (SALAMA and MORAD, 1976).

The isolated synaptic membrane preparation was first introduced as a means of studying the biochemical and/or enzymological characteristics of vertebrate presynaptic or postsynaptic membrane ( $c f$. RoDRIGUEZ DE LORES ARNAIZ and De Robertis, 1972; WhitTAKer, 1973). The results of the present study show that the isolated synaptic membrane ghosts preparation is also useful in in vitro study of many membrane functions coupled with membrane potential.

The authors express their gratitude to Drs. L. B. Cohen and A. Grinvald of Yale University for reading the manuscript and for helpful comments. We also appreciate the very valuable assistance of Dr. S. Tanaka in the electron microscopy, and we thank for Drs. N. Uyesaka and Y. Okada for help on the measure of cations. The work was partly supported by Grants 948112 and 978087 from the Ministry of Education, Science and Culture of Japan.

\section{REFERENCES}

Adelman, W. J. and Senft, J. P. (1968) Dynamic assymmetries in the squid axon membrane. J. Gen. Physiol., 51: 102S-114S.

Adrian, R. H. and Slayman, C. L. (1966) Membrane potential and conductance during transport of sodium, potassium and rubidium in frog muscle. J. Physiol., 184: 970-1014.

Blaustein, M. P. and Goldring, J. M. (1975) Membrane potentials in pinched-off presynaptic nerve terminals monitored with a fluorescent probe: evidence that synaptosomes have potassium diffusion potentials. J. Physiol. (Lond.), 247: 589-615.

COHEN, L. B. (1973) Changes in neuron structure during action potential propagation and synaptic transmission. Physiol. Rev., 53: 373.

Cohen, L. B., Salzberg, B. M., Davila, H. V., Ross, W. N., Landowne, D., Waggoner, A. S. and WANG, C. H. (1974) Changes in axon fluorescence during activity: molecular probe of membrane potential. J. Membr. Biol., 19: 1-36.

Davila, H. V., Salzberg, B. M., Cohen, L. B., and Waggoner, A. S. (1973) A large change in axon fluorescence that provides a promising method for measuring membrane potential. Nature (New Biol.), 241 : 159.

Goldman, D. E. (1943) Potential, impedance and rectification in membranes. J. Gen. Physiol., 
27: 37.

Gray, E. G. and Whittaker, V.P. (1962) The isolation of nerve endings from brain: An electron-microscopic study of cell fragments derived by homogenization and centrifugation. J. Anat., 96: 79-87.

Hodgkin, A. L. and KATZ, B. (1949) The effect of sodium ions on the electrical activity of the giant axon of the squid. J. Physiol., 108: 37-77.

Hoffman, J. E. and LARIS, P. C. (1974) Determination of membrane potentials in human and amphiuma red blood cells by means of a fluorescent probe. J. Physiol., 239: 519-552.

KAMINO, K. and INOUYE, A. (1975) Light-scattering characteristics of nerve-ending particles: Especially dissymmetry in unpolarized light. J. Colloid Interface Sci., 53: 275-281.

Kamino, K., Inouye, K., and Inouye, A. (1973) Potassium ion-induced swelling of nerve-ending particles by light-scattering measurements. Biochim. Biophys. Acta, 330: 39-52.

KAMINO, K., UyesAKA, N., and INOUYe, N. (1974) Calcium-binding of synaptosomes isolated from rat brain certex. I. Effects of high external potassium ions. J. Membr. Biol., 17: 13-26.

KeEN, P. and White, T. D. (1971) The permeability of pinched-off nerve endings to sodium, potassium and chloride and the effect of gramicidin. J. Neurochem., 18: 1097-1103.

LANDowne, D. (1975) Changes in fluorescence of skeletal muscle stained with merocyanine associated with excitation-contraction coupling. J. Gen. Physiol., 64: 5a.

Landowne, D., Potter, L. T., and Terrar, D. A. (1975) Structure-function relationships in excitable membrane. Ann. Rev. Physiol., 37: 485-508.

Laris, P. C., Pershadsingh, H. A., and Johnstone, R. H. (1976) Monitoring membrane potentials in Ehrlich ascites tumor cells by means of a fluorescent dye. Biochim. Biophys. Acta, 436: 475-488.

Lowry, O. H., Rosebrough, N. J., Farr, A. L., and Randall, R. J. (1951) Protein measurement with the Folin phenol reagent. J. Biol. Chem., 193: 265-275.

Oetliker, H., Baylor, S. M., and Chandler, W. K. (1975) Simultaneous changes in fluorescence and optical retardation in single muscle fibres during activity. Nature, 257: 693-696.

Podleski, T. and Changeaux, J. P. (1969) Effects associated with permeability changes caused by gramicidin A in electroplax membrane. Nature, 221: 541-545.

Rodriguez de Lores Arnaiz, G. and De Robertis, E. (1972) Properties of the isolated nerve endings. In: Current Topics in Membrane and Transport, ed. by BronNER, F. and KLEINzeller, A. Academic Press, New York, Vol. 3, pp. 237-272.

Ross, W. N., Salzberg, B. M., Cohen, L. B., Grinvald, A., Davila, H. V., Waggoner, A. S., and WANG, C. H. (1977) Changes in absorption, fluorescence, dichroism, and birefringence in stained gaint axons: optical measurement of membrane potential. J. Membr. Biol., 33: $141-183$.

SalzberG, B. M., Davila, H. V., and Cohen, L. B. (1973) Optical recording of impulses in individual neurons of an invertebrate central nervous system. Nature, 246: 508-509.

SAlamA, G. and Morad, M. (1976) Merocyanine 540 as an optical probe of transmembrane electrical activity in the heart. Science, 191: 485-487.

SHANES, A. M. (1958) Electrochemical aspects of physiological and pharmacological action in excitable cells. Part I. The resting cell and its alteration by extrinsic factors. Pharmacol. Rev., 10: 59-164.

Tedeschi, H. (1974) Mitochondrial membrane potential: Evidence from studies with a fluorescent probe. Proc. Natl. Acad. Sci. U.S.A., 71: 583.

WAGGoner, A. S. (1976) Molecular probes of membrane potential. J. Membr. Biol., 27: 317-334.

WhitTAKeR, V. P. (1973) The use of synaptosomes in the study of synaptic and neural membrane function. In: Structure and Function of Synapses, ed. by PAPPAS, G. D. and PurPURA, D. P. Raven Press, New York, pp. 87-102. 